\title{
Fluctuating asymmetry in vestigial and functional traits of a haplodiploid insect
}

\author{
BERNARD J. CRESPI* \& BRETT A. VANDERKIST \\ Department of Biosciences, Simon Fraser University, Burnaby BC, Canada V5A 1 S6
}

\begin{abstract}
If natural selection on fluctuating asymmetry (FA) is common and related to trait functionality, then vestigial traits should show elevated FA. Moreover, if FA increases with heterozygosity, then haploid males of haplodiploid taxa should exhibit higher FA than diploid females. We measured fluctuating asymmetry of functional traits (fore femora of soldier morphs and disperser morphs, and wings of dispersers) and a vestigial trait (wings of soldiers) in the eusocial haplodiploid gall thrips Oncothrips tepperi (Insecta: Thysanoptera). Wing FA, but not femur FA, was substantially and significantly higher in soldiers than in dispersers in both sexes. Patterns of intersexual variation in FA were complex: for wings, female soldiers had higher FA than male soldiers but male dispersers had higher FA than female dispersers, and for femora, males and females did not differ in FA in either morph. Our results suggest that vestigial traits exhibit higher FA because of relaxation of selection for functionality, and that haploidy does not necessarily lead to increased FA in males of haplodiploid taxa.
\end{abstract}

Keywords: fluctuating asymmetry, haplodiploidy, vestigial traits.

\section{Introduction}

Determination of the causes of variation among traits and individuals in fluctuating asymmetry (FA), random left and right deviations from bilateral symmetry, is an important unresolved question in the study of evolution and development (reviewed in Palmer \& Strobeck, 1986; Palmer, 1994, 1996). To address this question it is necessary to understand the patterns of causation of FA variability by genetic and epigenetic processes, and to analyse the presence and strength of phenotypic selection on FA.

The main hypothesized causes of FA variation among individuals, populations and species include heterozygosity, genes of large effect, inbreeding, stress and genomic co-adaptation (Parsons, 1990, 1992; Patterson \& Patton 1990; Clarke et al., 1992; Fowler \& Whitlock, 1994; Mitton, 1994; Polak \& Trivers, 1994). Of these, the role of heterozygosity in influencing FA has been especially controversial, because studies involving estimation of genome-wide heterozygosity, and studies of effects of inbreeding, have often yielded discordant results among taxa (e.g. Leary et al., 1984, 1985; Beacham \& Withler,

*Correspondence. E-mail: crespi@sfu.ca
1985, 1987; Clarke et al., 1986; Keller \& Passera, 1993; Mitton, 1994). Moreover, analysis of differences in FA between males and females of haplodiploid taxa have thus far been limited to a single, unusual species, the domesticated honeybee Apis mellifera (Brückner, 1975; Clarke et al., 1986, 1992; Clarke, 1993, 1995; Clarke \& Oldroyd, 1996; Messier \& Mitton, 1996; Smith et al., 1997; see also Keller \& Passera, 1993). As a result, effects of ploidy and heterozygosity on FA require further study before general conclusions can be drawn.

Analysing natural selection on FA has involved searching for correlations between FA and components of fitness (e.g. Markow \& Ricker, 1992; Harvey \& Walsh, 1993; Møller, 1994; Swaddle \& Cuthill, 1994; Leung \& Forbes, 1996), and testing for differences in FA between traits that vary in presumed level of functionality (Gummer \& Brigham, 1995), as suggested by Palmer \& Strobeck (1986) and Clarke (1993). Success of the former approach has been limited by: (1) disagreement over the presumed causes and objects of selection (e.g. Johnstone, 1994); (2) the presence of intersexual and interspecific patterns that dispute the role of sexual selection on FA (e.g. Balmford et al., 1993; Oakes \& Barnard, 1994; Evans et al., 1995; Tomkins \& Simmons, 1995); (3) serious methodological prob- 
lems involved in measuring and analysing FA (Palmer, 1994, 1996; Swaddle et al., 1994), especially the lack of quantification of measurement error (see Yezerinac et al., 1992); and (4) weak, nonsignificant correlations between FA of different traits among individuals within species (Dufour \& Weatherhead, 1996). Only one study has focused on effects of functionality on FA, reporting higher FA in the legs than the wings of a species of bat (Gummer \& Brigham, 1995). However, this study admittedly suffers from potential statistical difficulties, and a study of FA in multiple traits of blackbirds found apparently higher FA in wing measures than leg measures (Dufour \& Weatherhead, 1996). Thus, the intensity, objects and form of selection on FA, and the presence and magnitude of associations between 'genetic quality' and FA, remain largely obscure.

In this study we tested for effects of trait functionality and ploidy on FA in the haplodiploid gallforming thrips Oncothrips tepperi. This thrips exhibits two distinct morphs, winged dispersers and wingreduced 'soldiers' of both sexes that apparently do not leave their gall (Crespi, 1992a,b; Crespi \& Mound, 1997). Both dispersers and soldiers use their forelegs for fighting and walking, but only dispersers use their wings for flight; thus, wings in soldiers can be considered vestigial (reviewed in Fong et al., 1995). To analyse effects of trait functionality we compared FA in fore femur length and wing length between dispersers and soldiers, and to analyse effects of ploidy we compared FA for these two traits between haploid males and diploid females. We predicted: (i) higher FA in the wings of soldiers, which are vestigial, than in the functional wings of dispersers, but no difference between morphs for FA of the fore femora, which are functional in both morphs, and (ii) higher FA in haploid males than diploid females, if ploidy influences FA.

\section{Methods}

\section{Study animals}

Oncothrips tepperi forms galls on Acacia oswaldi in arid zone Australia (Crespi, 1992a,b; Crespi \& Mound, 1997; Crespi et al., 1997). Galls are initiated by single winged females, which fight each other over incipient galls. The offspring of foundresses feed, develop and eclose inside the gall. The first 2-10 individuals to eclose are 'soldier' females and males, which exhibit reduced wings and use their forelegs to defend the gall against invaders. Individuals that eclose later exhibit fully developed wings, and they disperse from the gall. As in almost all other cases of wing dimorphism, morphological and behavioural differences between soldiers and dispersers are apparently caused mainly by phenotypic plasticity rather than genetic differences between morphs (reviewed in Roff, 1990). Disperser sex ratios are typically about 1:6 female-biased (Crespi, 1992a, 1993), and females are moderately inbred, with an $F_{\text {IS }}$-value of $0.48(\mathrm{SE}=0.178)$ estimated from microsatellite typing of one locus for soldiers and dispersers from 11 galls (T. W. Chapman \& B. J. Crespi, unpubl. data).

\section{Collection and measurement}

The galls containing thrips were collected from a single tree $6 \mathrm{~km}$ west of Coolamon, New South Wales, on 23 June 1993, and stored in 100 per cent ethanol until measurement. Fore femora and forewings were removed and mounted on slides in Berlese mountant, and measured with a Mitutoyo 293 Series digital micrometer attached to a Wild M3Z microscope, to an accuracy of $0.001 \mathrm{~mm}$. Length was measured for fore femora, and wings were measured along their longitudinal axis, from the apex of the wing blade to the forewing scale (see fig. 38 of Stannard, 1968). We measured 9-10 female dispersers, 4-7 male dispersers and 1-4 female soldiers from each of six galls. For the dispersers, a sample of individuals of each sex was taken for measurement from each gall, but for female soldiers all of them within the galls were measured. Because soldiers are rare, we took them from 12 additional galls opened just for this purpose, and we were able to acquire and measure only 13 male soldiers from this collection site.

All measurements were conducted by the same individual, who was blind to the sex and morph (disperser or soldier) of the thrips being measured. Traits were measured twice on different days without reference to the previous measurement, to allow analysis and partitioning of measurement error (Palmer, 1994). A copy of the full data set is available upon request.

\section{Analysis}

Before analysing FA, we tested for the presence of directional asymmetry (following Palmer, 1994) and antisymmetry (by inspection of the distribution of right minus left differences). We used two measures of FA, the absolute value of the right minus left difference (averaged across the repeated measure- 
Table 1 Variation in wing length and femur length in different morphs and sexes of Oncothrips tepperi

\begin{tabular}{llccccc}
\hline Sex & Morph & $\begin{array}{c}\text { Wing length } \\
(\mathrm{mm})\end{array}$ & SD & $\begin{array}{c}\text { Femur length } \\
(\mathrm{mm})\end{array}$ & SD & $N$ \\
\hline Female & Disperser & 0.785 & 0.039 & 0.366 & 0.042 & 59 \\
Female & Soldier & 0.360 & 0.140 & 0.350 & 0.012 & 35 \\
Male & Disperser & 0.774 & 0.046 & 0.284 & 0.036 & 33 \\
Male & Soldier & 0.604 & 0.046 & 0.272 & 0.027 & 13 \\
\hline
\end{tabular}

ments) (FA1 of Palmer, 1994, which is the FA measure reported in most studies), and Palmer's (1994) FA10, which represents the magnitude of FA after measurement error has been removed. Before computing and using these FA measures, we tested for the presence of true FA by determining whether or not FA variation was significantly larger than measurement error (Palmer, 1994).

The relatively small size of our sample of soldier males $(N=13)$ may downwardly bias the estimate of their FA values. To investigate this possibility, we randomly sampled sets of 13 soldier females without replacement 10 times, calculated mean FA1 and FA10 values for each of these 10 subsamples, and compared them to the mean FA1 and FA10 values for the full data set of 35 female soldiers. For wings of soldier females, observed mean FA1 (with $N=35$ ) was 4 per cent higher than the mean FA1 from 10 random subsamples (of $N=13$ ), and observed FA10 was 14 per cent higher than FA10 from subsamples. For femora of soldier females, observed FA1 (with $N=32$ ) was 30 per cent higher than FA1 from subsamples (of $N=13$ ), and observed FA10 was 19 per cent higher than FA10 from subsamples (see Table 2 for observed values). We conclude that our FA values for soldier males are probably downwardly biased by approximately these amounts, and we interpret our results accordingly.

Statistical analyses were conducted in Systat, Statview, and using an Excel spreadsheet, based on formulae and analyses in Palmer (1994). Note that parametric tests using FA1 correspond to Levene's test of variance heterogeneity (see Palmer, 1994, section 13.2), and are thus statistically valid despite the truncated normal distribution of the data. Tests comparing samples using FA10, a measure of FA corrected for measurement error, involve simple $F$-tests comparing variances (Palmer, 1994, section 13.1). Degrees of freedom for FA10 are approximate (Palmer, 1994, section 3.2) and are rounded down for variance comparisons to make these tests more conservative.

\section{Results}

Character size, measurement error and asymmetry

Soldiers had shorter wings than dispersers in both females $(t=21.8, P<0.001)$ and males $(t=11.3$, $P<0.001$ ) (Table 1). By contrast, disperser females had slightly longer fore femora than soldier females $(t=2.14, P<0.05)$, but disperser males did not differ from soldier males in femur length $(t=1.13$, $P>0.25)$.

No significant directional asymmetry was found in any of the samples for either trait $(P>0.05$ for each sex-morph-trait combination), nor did histograms of FA1 reveal any sign of bimodality that would indicate the presence of antisymmetry. Fluctuating asymmetry was significantly larger than measurement error in all of the samples $(P<0.05$ for the femora of soldier males, $P<0.0025$ for all others). Individuals from different galls did not vary in FA1 for either trait in disperser males or in disperser females (ANOvas, $P>0.35$ for each test). By contrast, trait size varied significantly among galls for disperser female wings and femora, and for disperser male wings (ANOVAs, $P<0.025$ for each test; $P=0.064$ for disperser male femora; within-gall samples were too small to conduct these tests with soldiers). Wing FA1 was uncorrelated with femur FA1 in female dispersers (product-moment correlation, $r=0.127)$, female soldiers $(r=-0.069)$, male dispersers $(r=-0.031)$, and male soldiers ( $r=0.053$; all nonsignificant at $P>0.25$, sample sizes as in Table 2).

\section{Effects of sex and morph on FA}

We compared FA1 between the two morphs, and between females and males, using two-way ANOvAs (Table 3). For wings, there was a strong, significant effect of morph, with FA1 about 10 times higher in soldier females than in disperser females and about four times higher in soldier males than in disperser males (Tables 2 and 3). Wing FA corrected for measurement error (FA10 in Table 2) exhibited an 
Table 2 Variation in fluctuating asymmetry by trait, sex, and morph in Oncothrips tepperi

\begin{tabular}{lllccccr}
\hline Trait & Sex & Morph & Mean FA1 & SE & $N$ & \multirow{2}{*}{ FA10 } & d.f. \\
\hline Wing & Female & Disperser & 0.008178 & 0.000821 & 59 & 0.000037 & 31.42 \\
& Female & Soldier & 0.086400 & 0.014307 & 35 & 0.007326 & 33.75 \\
& Male & Disperser & 0.010697 & 0.001933 & 33 & 0.000085 & 19.34 \\
& Male & Soldier & 0.042231 & 0.012807 & 13 & 0.001955 & 11.86 \\
Femur & Female & Disperser & 0.006407 & 0.000565 & 59 & 0.000019 & 29.91 \\
& Female & Soldier & 0.007266 & 0.001137 & 32 & 0.000021 & 9.73 \\
& Male & Disperser & 0.006281 & 0.000801 & 32 & 0.000015 & 9.49 \\
& Male & Soldier & 0.006385 & 0.000836 & 13 & 0.000011 & 3.17 \\
\hline
\end{tabular}

Mean FA1, the mean of the unsigned difference between rights and left sides, for the two measurements of each trait (FA1 of Palmer, 1994); FA10, FA corrected for measurement error (FA10 in Palmer, 1994). Among-group comparisons using FA10 involve $F$-tests of variance (e.g. to compare soldier females vs. disperser females for wing FA10, we compute

$F_{31,33}=0.007326 / 0.000037=198 ; P<0.001$; see Palmer, 1994, section 13.1).

even stronger pattern: wing FA10 was about 200 times higher in soldier females than in disperser females $\left(F_{31,33}=198 ; P<0.001\right)$, and almost 25 times higher in soldier males than in disperser males $\left(F_{11,19}=23 ; P<0.001\right)$. The magnitude of these mean differences indicates that downward bias in variance for male soldiers, caused by their small sample size, cannot be responsible for the observed patterns.

For femora, FA1 values were similar between morphs in both sexes (Table 2), and the two-way ANOVA indicated a lack of significant difference between morphs (Table 3). Similarly, there were no differences in FA10 for either comparison $(P>0.25$ for each).

Our prediction of consistently higher FA in males than in females was not supported. For femora, there were no significant differences between the two sexes for FA1 (Tables 2 and 3). By contrast, the two-way ANOvA of wing FA1 (Table 3) yielded a significant sex-by-morph interaction effect, which indicates that any differences between the sexes differ between the morphs. In particular, mean FA1 was about twice as large for soldier females than soldier males, and about 20 per cent larger in disperser males than disperser females (Table 2).

Patterns of intersexual difference in FA10 paralleled those for FA1. Thus, for wings, FA10 was higher in disperser males than in disperser females $\left(F_{19,31}=2.30 ; P<0.05\right)$; by contrast, FA10 was higher in soldier females than in soldier males $\left(F_{33,11}=3.75\right.$; $P<0.01)$. For femora, intersexual comparisons of both dispersers and soldiers for FA10 showed a lack of significance $(P>0.20$ for each).

A possible explanation for the high FA1 and FA10 in wings of soldier females relative to soldier males follows from inspection of the relationships

Table 3 Results of two-way ANovAs, analysing the effects of morph (soldier vs. disperser) and sex (female vs. male) on wing FA1 and femur FA1 variation in Oncothrips tepperi

\begin{tabular}{llrcc}
\hline Trait & Source of variation & d.f. & MS & $F$ \\
\hline Wing FA1 & Morph & 1 & 0.07887 & $38.94^{* * *}$ \\
& Sex & 1 & 0.01136 & $5.61^{*}$ \\
& Morph $\times$ sex & 1 & 0.01427 & $7.05^{* *}$ \\
& Error & 136 & 0.00203 & \\
Femur FA1 & Morph & 1 & 0.000006 & 0.25 \\
& Sex & 1 & 0.000006 & 0.27 \\
& Morph $\times$ sex & 1 & 0.000004 & 0.15 \\
& Error & 132 & 0.000024 & \\
\hline
\end{tabular}

${ }^{*} P<0.05 ;{ }^{* *} P<0.01 ;{ }^{* *} P<0.000001$. 
between wing length and wing FA1 in the two sexes of soldiers (Fig. 1). There is a significant negative relationship between wing length and wing FA1 for soldiers in both males (product-moment correlation, $r=-0.86, P<0.001, N=13$ ) and females $(r=-0.36, \quad P<0.05, \quad N=35)$. Moreover, soldier females have substantially smaller wings than do soldier males $(t=6.0, P<0.001$; by contrast, $t=1.2$, $P>0.2$, for the comparison of disperser male with disperser female wing length). These analyses suggest the presence of a quantitative dimension to vestigiality in soldiers, such that as wings become
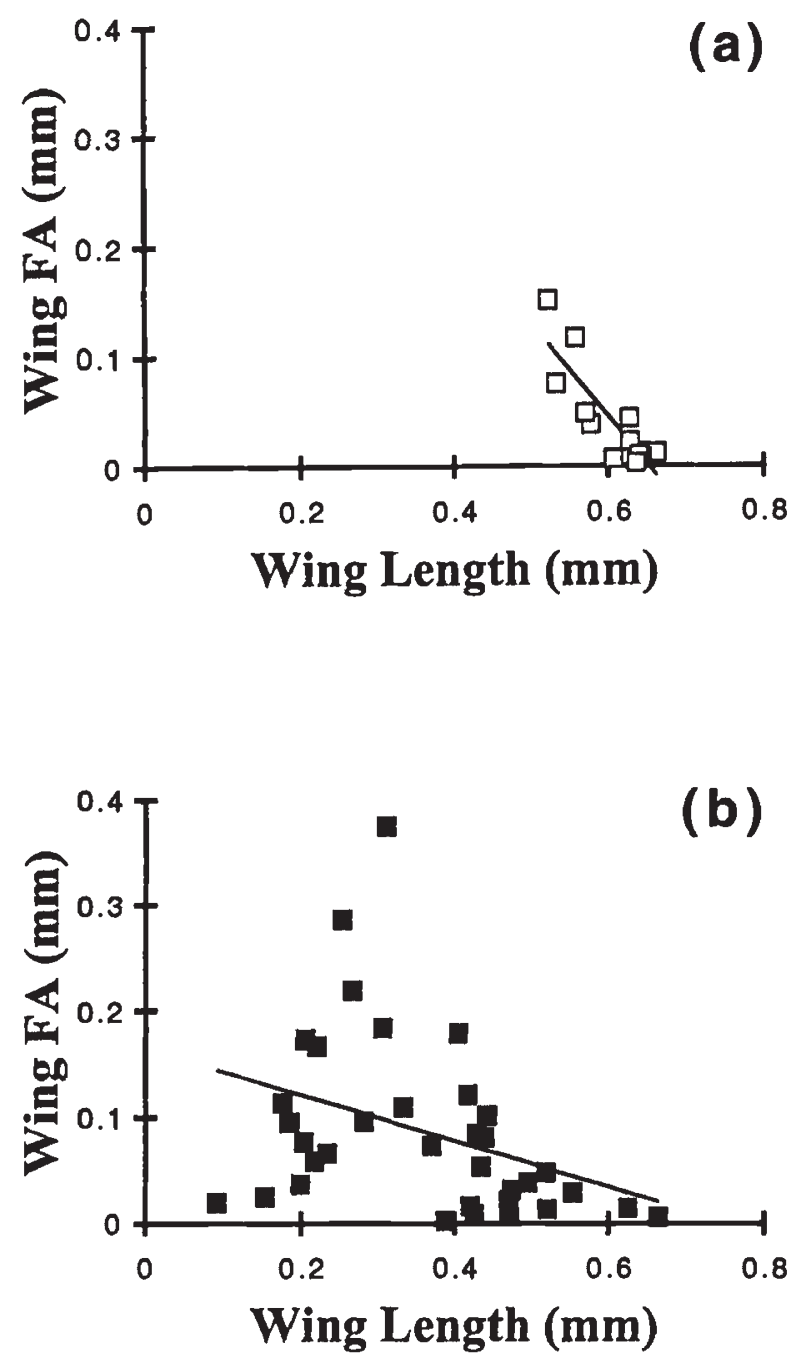

Fig. 1 The relationship between wing length (mean of the two measurements) and wing fluctuating asymmetry (FA1) in (a) soldier males and (b) soldier females of Oncothrips tepperi. Note that a significant difference in slope between the sexes (ANCOVA, $F_{1,45}=11.53 P<0.01$ ) precludes intersexual comparison of wing length-adjusted mean FA1. smaller and more vestigial (in a developmental rather than a functional sense), their level of FA increases. Thus, if the wings of soldier males are less vestigial than the wings of soldier females, this difference could help explain the finding that soldier males have low wing FA1 relative to soldier females. The argument that these negative correlations between wing length and wing FA1 are artefacts of measurement variation jointly and differently affecting both axes is weakened by the observations that: (i) the same relationship is weak and nonsignificant for disperser males $(r=-0.19, P>0.25, N=33)$ and disperser females $(r=-0.14, P>0.25, N=59)$, and (ii) correlations between repeated measurements of left and right wing lengths in soldiers range from 0.993 to 0.999 , which suggests that measurement variation is small relative to the magnitude of these patterns.

\section{Discussion}

We have documented the presence of substantially higher levels of fluctuating asymmetry in individuals for whom wings are vestigial (soldier morphs) than in individuals for whom this same trait is functional (dispersers). Moreover, a trait that is functional in both soldiers and dispersers, femur length, did not vary in FA between morphs in either sex. These data provide the first evidence of relatively high FA in vestigial traits, and they suggest that canalization of development is relaxed in such traits because of the absence of selection on functionality. Future analysis of mechanisms involved in the development of functional vs. vestigial traits may provide important information concerning the genetic and ontogenetic basis of FA variation.

The hypothesis that haploid males of Oncothrips tepperi show consistently higher FA than diploid females was not supported by the data. Instead, we uncovered complex interactions between morph and sex, manifested in high wing FA of soldier females relative to soldier males and high wing FA of disperser males relative to disperser females. The relatively high wing FA of soldier females may be related to the smaller wing size of these individuals than soldier males, such that smaller wings are for some reason less canalized and exhibit higher FA (see Tague, 1997). However, this argument cannot apply to the higher wing FA of disperser males than disperser females (for FA10), because wings of dispersing males and dispersing females do not differ substantially or significantly in length. We also note that our FA measure with correction for measurement error (FA10) revealed statistically 
significant intersexual patterns that were not as clearly demonstrable with the uncorrected FA measure (FA1). These findings should encourage future researchers studying FA variation to correct for measurement error as an integral part of their analyses (see also Palmer, 1996).

Because $O$. tepperi exhibits inbreeding, which is consistent with its female-biased sex ratio (Crespi, 1992a,b, 1993; T. W. Chapman \& B. J. Crespi, unpubl. data), differences in heterozygosity between males and females that could contribute to intersexual FA variation are smaller than in outbred species. However, we note that higher FA in males than females is retained under high inbreeding levels in the haplodiploid bee Apis mellifera (Clarke et al., 1986, 1992), which suggests that if there were intersexual FA differences arising from ploidy alone, they should be apparent even though $O$. tepperi inbreeds. Further tests of the influences of ploidy and heterozygosity on FA could use additional haplodiploid taxa such as some beetles, other thrips, nematodes, mites or rotifers (see Wrensch \& Ebbert, 1993), and couple FA analysis with measurement and manipulation of genetic variation.

\section{Acknowledgements}

We thank Rich Palmer, Geoff Clarke and Mike Whitlock for helpful comments and discussion, and Rich Palmer for providing the Excel spreadsheet. We are grateful to NSERC and the NDP for financial support.

\section{References}

BALMFORD, A., JONES, 1. L. AND THOMAS, A. L. R. 1993. On avian asymmetry: evidence of natural selection for symmetrical tails and wings in birds. Proc. R. Soc. B, 252, 245-251.

BEACHAM, T. D. AND WITHLER, R. E. 1985. Heterozygosity and morphological variability of chum salmon (Oncorhynchus keta) in southern British Columbia. Heredity, 54, 313-322.

BEACHAM, T. D. AND WITHLER, R. E. 1987. Developmental stability and heterozygosity in chum (Oncorhynchus keta) and pink (Oncorhyncus gorbuscha) salmon. Can. J. Zool., 65, 1823-1826.

BRÜCKNER, D. 1975. The influence of genetic variability on wing symmetry in honybees (Apis mellifera). Evolution, 30, 100-108.

ClARKE, G. M. 1993. The genetic basis of developmental stability. I. Relationships between stability, heterozygosity and genomic coadaptation. Genetica, 89, 15-23.

ClARKE, G. M. 1995. The genetic basis of developmental stability. II. Asymmetry of extreme phenotypes revisited. Am. Nat., 146, 708-725.
ClARKE, G. M. AND OLDROYD, B. P. 1996. The genetic basis of developmental stability in Apis mellifera. II. Relationships between character size, asymmetry and singlelocus heterozygosity. Genetica, 97, 211-224.

ClARKE, G. M., BRAND, G. W. AND WHITTEN, M. J. 1986. Fluctuating asymmetry: a technique for measuring developmental stress caused by inbreeding. Aust. J. Biol. Sci., 39, 145-153.

ClARKE, G. M., OLDROYD, B. P. AND HUNT, P. 1992. The genetic basis of developmental instability in Apis mellifera: heterozygosity vs. genetic balance. Evolution, 46, $753-762$.

CRESP1, B. J. 1992a. The behavioral ecology of Australian gall thrips. J. Nat. Hist., 26, 769-809.

CRESP1, B. J. 1992b. Eusociality in Australian gall thrips. Nature, 359, 724-726.

CRESPI, B. J. 1993. Sex ratio selection in Thysanoptera. In: Wrensch, D. L. and Ebbert, M. (eds) Evolution and Diversity of Sex Ratio in Insects and Mites, pp. 214-234. Chapman \& Hall, New York.

CRESPI, B. J., AND MOUND, L. A. 1997. Ecology and evolution of social behavior among Australian gall thrips and their allies. In: Choe, J. and Crespi, B. J. (eds) The Evolution of Social Behavior in Insects and Arachnids, pp. 166-180. Cambridge University Press, Cambridge.

CRESP1, B. J., CARMEAN, D. AND CHAPMAN, T. w. 1997. The ecology and evolution of galling thrips and their allies. Annu. Rev. Ent., 42, 51-71.

DUfour, K. W. AND WEATHERHEAD, P. J. 1996. Estimation of organism-wide asymmetry in red-winged blackbirds and its relation to studies of mate selection. Proc. $R$. Soc., B, 263, 769-775.

EVANS, M. R. AND BARNARD, P. 1995. Variable sexual ornaments in scarlet-tufted malachite sunbirds (Nectarinia johnstoni) on Mount Kenya. Biol. J. Linn. Soc., 54, 371-381.

EVANS, M. R., MARTINS, T. L. AND HALEY, M. P. 1995. Interand intra-sexual patterns of fluctuating asymmetry in the red-billed streamertail: should symmetry always increase with ornament size? Behav. Ecol. Sociobiol., 37, 15-23.

FONG, D. W., KANE, T. C. AND CULVER, D. C. 1995 . Vestigialization and loss of non-functional characters. Ann. Rev. Ecol. Syst., 26, 249-268.

FOWLER, K. AND WHITLOCK, M. C. 1994. Fluctuating asymmetry does not increase with moderate inbreeding in Drosophila melanogaster. Heredity, 73, 373-376.

GUMMER, D. L. AND BRIGHAM, R. M. 1995. Does fluctuating asymmetry reflect the importance of traits in little brown bats (Myotis lucifugus)? Can. J. Zool., 73, 990-992.

HARVEY, I. F. AND WALSH, K. J. 1993. Fluctuating asymmetry and lifetime mating success are correlated in males of the damselfly Coenagrion puella (Odonata: Coenagrionidae). Ecol. Entomol., 18, 198-202.

JOHNSTONE, R. A. 1994. Female preference for symmetrical males as a by-product of selection for mate recognition. Nature, 373, 172-175. 
KELLER, L. AND PASSERA, L. 1993. Incest avoidance, fluctuating asymmetry, and the consequences of inbreeding in Iridomyrmex humilis, an ant with multiple queen colonies. Behav. Ecol. Sociobiol., 33, 191-199.

LEARY, R. F., ALLENDORF, F. W. AND KNUDSEN, K. L. 1984. Superior developmental stability of heterozygotes at enzyme loci in salmonid fishes. Am. Nat., 124, 540-551.

LEARY, R. L., ALLENDORF, F. W., KNUDSEN, K. L. AND THORGAARD, G. H. 1985. Heterozygosity and developmental stability in gynogenetic diploid and triploid rainbow trout. Heredity, 54, 219-225.

LEUNG, B. AND FORBES, M. R. 1996. Fluctuating asymmetry in relation to stress and fitness: effects of trait type as revealed by meta-analysis. Ecoscience, 3, 400-413.

MARKOW, T. AND RICKER, J. P. 1992. Male size, developmental stability, and mating success in natural populations of three Drosophila species. Heredity, 69, 122-127.

MESSIER, s. AND MITTON, J. B. 1996. Heterozygosity at the malate dehydrogenase locus and developmental homeostasis in Apis mellifera. Heredity, 76, 616-622.

MitTon, J. в. 1994. Enzyme heterozygosity, metabolism, and developmental stability. In: Markow, T. A. (ed.) Developmental Instability: its Origins and Evolutionary Implications, pp. 49-67. Kluwer Academic Publishers, Dordrecht, The Netherlands.

MøLLER, A. P. 1994. Sexual selection in the barn swallow (Hinundo rustica). IV. Patterns of fluctuating asymmetry and selection against asymmetry. Evolution, 48, 658-670.

MøLleR, A. P. AND HÖGLUND, J. 1991. Patterns of fluctuating asymmetry in avian feather ornaments: implications for models of sexual selection. Proc. $R$. Soc. B, 245, $1-5$.

OAKES, E. J. AND BARNARD, P. 1994. Fluctuating asymmetry and mate choice in paradise whydahs, Vidua paradisaea: an experimental manipulation. Anim. Behav., 48, 937-943.

PALMER, A. R. 1994. Fluctuating asymmetry analyses: a primer. In: Markow, T. A. (ed.) Developmental Instability: its Origins and Evolutionary Implications, pp. 335-364. Kluwer Academic Publishers, Dordrecht, The Netherlands.
PALMER, A. R. 1996. Waltzing with asymmetry. Bioscience, 46, 518-532.

PALMER, A. R. AND STROBECK, C. 1986. Fluctuating asymmetry: measurement, analysis, patterns. Ann. Rev. Ecol. Syst., 17, 391-421.

PARSONS, P. A. 1990. Fluctuating asymmetry: an epigenetic measure of stress. Biol. Rev., 65, 131-145.

PARSONS, P. A. 1992. Fluctuating asymmetry: a biological monitor of environmental and genomic stress. Heredity, 68, 361-364.

PATTERSON, B. D. AND PATTON, J. L. 1990. Fluctuating asymmetry and allozymic heterozygosity among natural populations of pocket gophers (Thomomys bottae). Biol. J. Linn. Soc., 40, 21-36.

POLAK, M. AND TRIVERS, R. 1994. The science of symmetry in biology. Trends Ecol. Evol., 9, 122-124.

ROFF, D. A. 1990. The evolution of flightlessness in insects. Ecol. Monogr., 60, 389-421.

SMITH, D. R., CRESP1, B. J. AND BOOKSTEIN, F. L. 1997. Asymmetry and morphological abnormality in bees Apis mellifera: effects of ploidy and hybridization. J. Evol. Biol. (in press).

STANNARD, L. J. 1968. The thrips, or Thysanoptera of Illinois. Illinois Natural History Survey Bulletin, 29, 1-552.

SWADDLE, J. P. AND CUTHILl, 1. C. 1994. Female zebra finches prefer males with symmetric chest plumage. Proc. R. Soc., B, 258, 267-271.

SWADDle, J. P., WITTER, M. S. AND CUTHILl, I. C. 1994. The analysis of fluctuating asymmetry. Anim. Behav., 48, 986-989.

TAGUE, R. G. 1997. Variability of a vestigial structure: first metacarpal in Colobus guereza and Ateles geoffroyi. Evolution, 51, 595-605.

TOMkins, J. L. AND simmons, L. w. 1995. Patterns of fluctuating asymmetry in earwig forceps: no evidence for reliable signalling. Proc. $R$. Soc. B, 259, 89-96.

WRENSCH, D. L. AND EBBERT, M. A. 1993. Evolution and Diversity of Sex Ratio in Insects and Mites. Chapman \& Hall, New York.

YEZERINAC, S, M., LOUGHEED, S. C. AND HANDFORD, P. 1992. Measurement error and morphometric studies: statistical power and observer experience. Syst. Biol., 41, 471-482. 